\title{
Protocolling the TINATEL-System: A Contribution for Long Term Evaluation of an AAC-System for Speech Impaired Persons to Access the Public Telephone Network
}

\author{
Paul Panek \\ fortec - Working Group on Rehabilitation-Engineering \\ Vienna University of Technology
}

\begin{abstract}
This paper describes the long-term evaluation of the TINATELSystem, an Alternative and Augmentative Communication (AAC) device to be used for aided communication within the public telephone network. The system was especially developed for a single speech impaired User. An integrated logbook recorded a lot of data between 1991 and 1994 concerning the daily use of the system. These data are described and shown in different ways to keep in view the transferrate, the average daily duration of use, the social and therapeutical effects and so on.

Some general aspects of protocolling data by an AAC system are shown. It is stated that these data can contribute valuable parts to the evaluation of $\mathrm{AAC}$ devices.
\end{abstract}

\section{Background / Description of the TINATEL-System}

The TINATEL-System, published in [10], has been in day by day use since November 1991. This paper gives a survey of the recorded data which have been collected by the TINATEL-System within 30 months. Recently an increasing amount of papers concerning the importance of evaluation in Rehabilitation Technology has been published ([4], [7], [14], [3], [11]). It is an aim of this paper to give an impression how the recorded data could be used to help evaluating AAC-devices.

\subsection{Description of the TINATEL-System}

The TINATEL-System consists of a PC/AT286, a speech synthesizer, an interface to the telephone network with an auto dialler, a hand-free talking device and a system software for building up the User interface. The input is done by the User with the help of a headstick and a keyboard with a keyguard. The system's output is realised by a VGA and a speech synthesizer.

The TINATEL-System was developed and implemented for a single User. Therefore it was possible to adapt the system to the individual and personal needs of the User. The User herself is severely physically handicapped in motorial control of her movements. She is not able to speak herself. She is doing the System's input with a headstick and an adapted keyboard. The keys pressed by the User are synthesized by the speech synthesizer and transferred to the communication partner via the 
public telephone network. In this way the counterpart can hear all the keys pressed by the User and is able to combine the single characters to whole words and sentences. There is also the possibility to use pre-stored phrases which are not spelled letter by letter but are synthesized as whole sentences.

With the help of the TINATEL-System the User is able to strike up a conversation with every member of the public telephone network. The things said by the counterpart get audible for the AAC-User by the hand-free talking device integrated in the TINATEL-System. The principle of the aided communication is shown in Fig. 1 with reference to the work of C. Bühler et al. [6].

The User lives in a family environment and uses the TINATEL-System for communication with her friends. From the start the TINATEL-Project had very good working conditions. The User has had high interest and motivation to get into contact with High-Tech aids. Also there has been a great need to find a more effective way to communicate with other persons. M. Scherer describes the importance of a good relationship of environment, personal and technology aspects in her "Matching Person and Technology" model, published in [15].

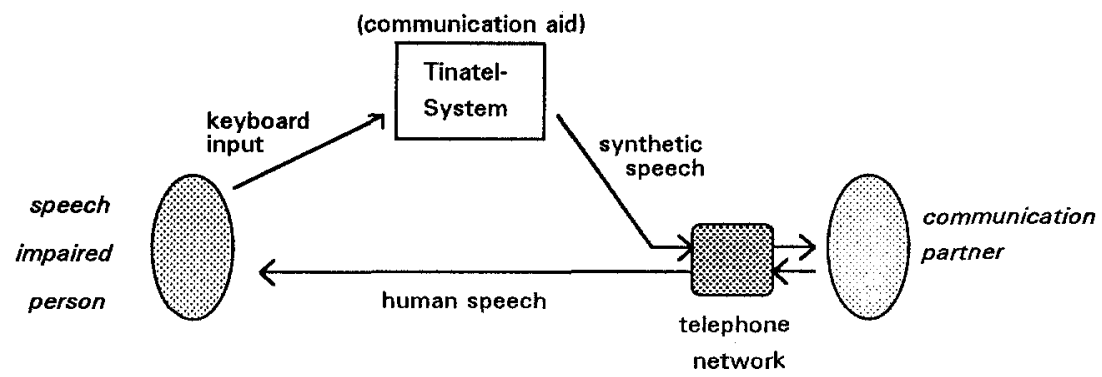

Fig. 1. Principle of the aided communication realised in the TINATEL-System.

\section{Collecting the Data / Methods of Recording}

The data described in the following sections were recorded in two different ways: automatically and manually. The automatic recording offers information about the number of calls and the duration of these calls. Manual recording allows to analyse the internal structure of the User's calls.

\subsection{Automatic Recording}

The TINATEL-System is automatically recording the system events which occur during use of the system. The recorded data consist of date and time of the daily start up and termination of the system, time of the beginning and termination of a telephone call (only calls initiated by the system!) and the telephone number dialled by the system. The data covers the period from November 1991 until April 1994, these are 30 months. 


\subsection{Manual Recording}

14 telephone calls initiated by the TINATEL-User were recorded manually. These calls took place in three periods: January-Juny 1992, March-May 1993 and FeberApril 1994. The recording was done by manually taking notes of all the information sent by the system. The actually recording of the data was done by the communication partner ${ }^{1}$. During the 14 recorded calls only the spelling mode was used (the system spells letter by letter as the keys are pressed by the User). Prestored phrases were not used. In general the topics of the calls came from the private area. The recorded data consist of the number of keys pressed by the User and the number of characters predicted by the communication partner during the telephone call.

\section{Presentation of the Recorded Data}

\subsection{Data from the Automatic Recording}

Preparation of the Primary data. First the data which had been primarily recorded were transformed off-line into records. Each of these records describes one telephone call. A record contains the following information:

- Date of the call,

- Duration (T) of the call and

- Dialled number (= communication partner).

These records of data are describing a period of 30 months. Within this period a number of 1815 calls had been recorded by the TINATEL-System. During the offline preparation the data records of 48 calls $(2.6 \%)$ had to be eliminated because of incompleteness ${ }^{2}$.

The system does not verify the status of the telephone line. Therefore the recorded data do not include any information concerning the question if the communication partner really had picked up the receiver. To handle this a limit of time (2 minutes) is introduced. Only those calls which lasted for longer than two minutes are stated to be "real" calls; all the others are eliminated because the communication partner probably did not pick up the receiver. In the following only the 534 calls which lasted longer than 2 Minutes are used (Fig. 2).

\begin{tabular}{|l|c|}
\hline $\begin{array}{l}\text { Total number of calls initiated by the TINATEL- } \\
\text { System (November } 1991 \text { - April 1994) }\end{array}$ & 1815 \\
\hline completely recorded calls & 1767 \\
\hline completely recorded and longer than 2 minutes & 534 \\
\hline
\end{tabular}

Fig. 2. Number of automatically recorded calls.

1 Restriction: all 14 calls were done with the same communication partner.

2 Their data records did not include the termination time. Therefore it is not possible to calculate the duration of the call. 
Presentation of the Automatically Recorded Data. The data can be shown in different ways. In Fig. 3 there is a presentation concerning the duration of the calls within each month. The total duration of all 534 calls is 224 hours, the average is 7.5 hours per month.

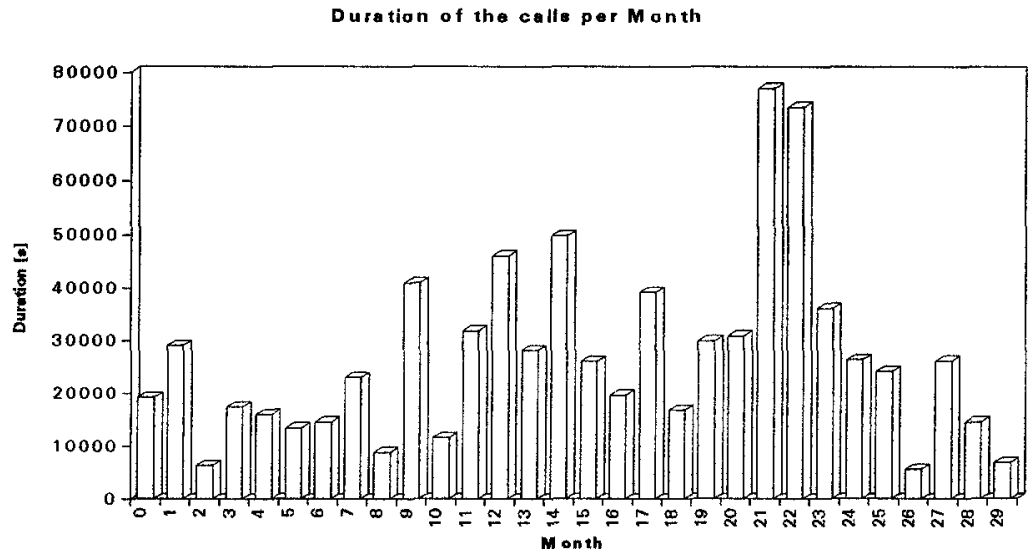

Fig. 3. Total duration per month of the calls initiated by the TINATEL-System. (only calls with T>2 minutes, total duration: 224 hours, total number of calls: 534).

The same data can be presented in order to show the monthly amount of calls build up by the system as well. This is done in Fig. 4. The average number of calls is $534 / 30=17,8$ calls per month.

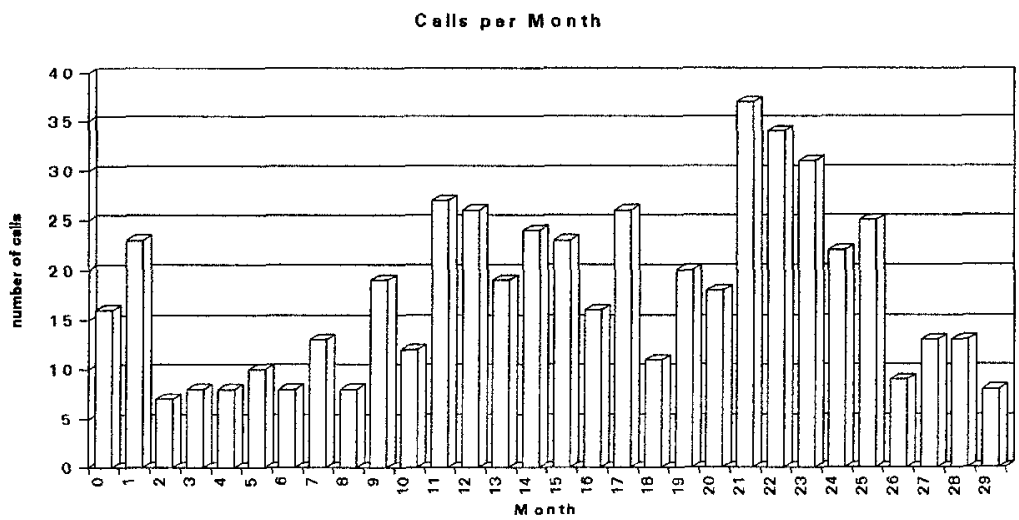

Fig. 4. Number of calls per month initiated by the TINATEL-System (only calls with T>2 minutes, total number of calls: 534). 


\subsection{Data from the Manual Recording}

14 calls have been recorded manually in order to get the following data (Fig. 5):

- Date and duration (T) of the call,

- Number of the correctly pressed keys (characters) (C),

- Number of mistyped keys (M), immediately corrected by the User with the help of the delete key,

- Number of times the delete key was pressed (DEL, with $D E L=M$ ),

- Number of the mistyped but not corrected characters (Mnc) and the

- Number of letters predicted by the communication partner $(\mathrm{P})$.

\begin{tabular}{|r|r|r|r|r|r|r|r|r|}
\hline Date & $\begin{array}{r}\text { T } \\
\text { [min] }\end{array}$ & $\begin{array}{r}\mathbf{C} \\
\text { [char] }\end{array}$ & $\begin{array}{r}\mathbf{P} \\
\text { [char] }\end{array}$ & $\begin{array}{r}\text { M } \\
\text { [char] }\end{array}$ & $\begin{array}{r}\text { DEL } \\
\text { [char] }\end{array}$ & $\begin{array}{r}\text { Mnc } \\
\text { [char] }\end{array}$ & $\begin{array}{r}\text { NTR } \\
\text { [char/min] }\end{array}$ & $\begin{array}{r}\text { NTR_max } \\
\text { [char/min] }\end{array}$ \\
\hline 210292 & 30 & 189 & 26 & 46 & 46 & 0 & 7.16 & 10.23 \\
\hline 130392 & 135 & 1524 & 330 & 123 & 123 & 40 & 13.73 & 15.85 \\
\hline 240492 & 32 & 300 & 46 & 45 & 45 & 8 & 10.81 & 13.88 \\
\hline 190592 & 63 & 755 & 49 & 37 & 37 & 9 & 12.76 & 14.08 \\
\hline 90692 & 89 & 1602 & 75 & 188 & 188 & 52 & 18.84 & 23.65 \\
\hline 200393 & 70 & 1324 & 239 & 122 & 122 & 56 & 22.33 & 26.61 \\
\hline 30493 & 24 & 272 & 96 & 9 & 9 & 1 & 15.33 & 16.12 \\
\hline 90493 & 58 & 647 & 81 & 55 & 55 & 13 & 12.55 & 14.67 \\
\hline 140493 & 38 & 644 & 107 & 57 & 57 & 12 & 19.76 & 23.08 \\
\hline 230493 & 35 & 402 & 107 & 19 & 19 & 14 & 14.54 & 16.03 \\
\hline 80593 & 28 & 484 & 119 & 51 & 51 & 11 & 21.54 & 25.57 \\
\hline 110294 & 24 & 623 & 17 & 14 & 14 & 0 & 26.67 & 27.83 \\
\hline 180394 & 39 & 430 & 54 & 28 & 28 & 7 & 12.41 & 14.03 \\
\hline 40494 & 29 & 573 & 51 & 25 & 25 & 6 & 21.52 & 23.45 \\
\hline
\end{tabular}

Fig. 5. Manually recorded calls.

Explanation. When the User types with her headstick a wrong key, then this key will be transmitted via speech synthesizer and telefon line, too. If the User notices the mistyped key, she can make a correction by pressing the delete key which would transmit the message "Wrong key typed!" to the communication partner or she can believe in her communication partner's ability to recognise and correct the mistyped letter by his own. In the last case she will not press the delete key but continue in typing the word she wants to say. The communication partner is able to predict a word by guessing which letters might follow those which have already been transmitted.

It seems to be interesting how this contribution of transferred characters changes during the period of 30 months. Therefore all 14 manually recorded calls have been put into a diagramm (Fig. 6) showing the relationship between correct, predicted, mistyped and corrected, mistyped and not corrected characters. 
Ratio of Transmitted Keys

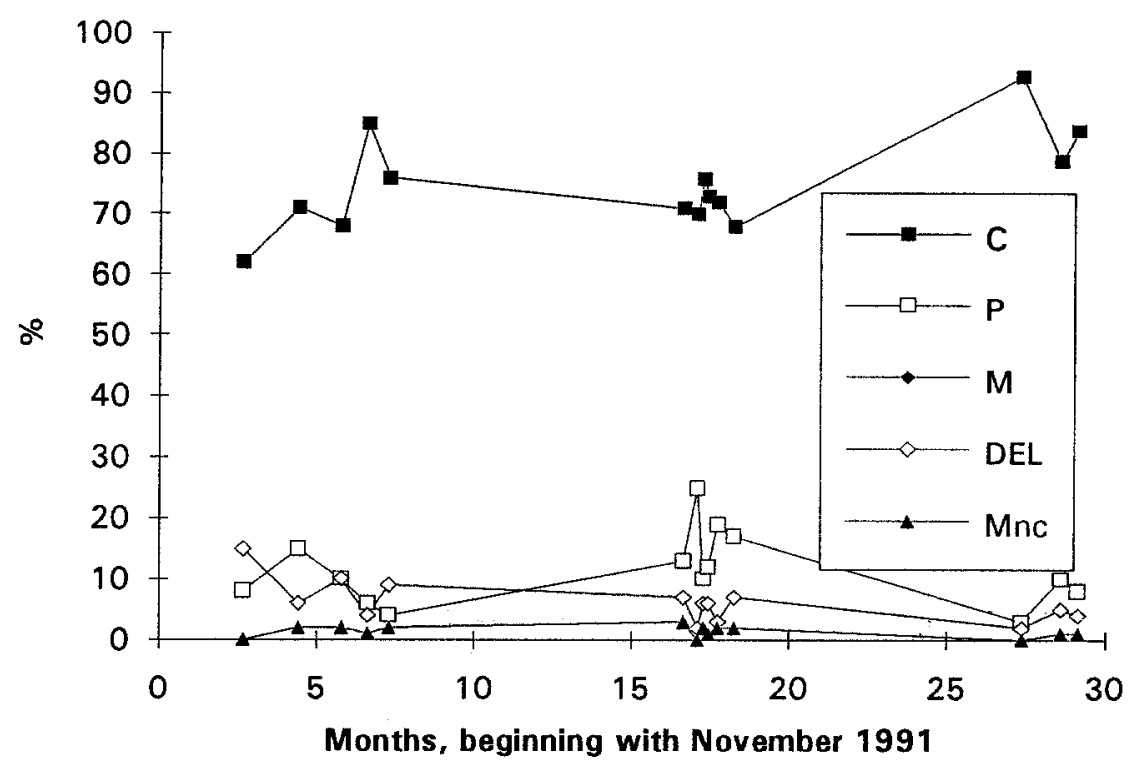

Fig. 6. Ratio of the keys pressed by the TINATEL-User.

Transfer Rate. Another point of view is the transfer of information from the AACUser towards the communication partner. A first step was done in [10]. The NettoTransferrate is introduced. It describes the amount of characters transmitted to the communication partner related to the duration of the communication.

$$
N T R:=\frac{C+P}{T} \quad \text { (Eq. 1) }
$$

It is to say that only $\mathrm{C}$ characters are really transmitted via telephone line. $P$ characters had been predicted by the communication partner. The quantities of DEL, $M$ and Mnc do increase the number of transferred characters but do not increase the transferred information (Eq. 1).

As a second variable

$$
N T R_{\max }:=\frac{C+P+M+D E L+M n c}{T}(E q .2)
$$

is defined. NTRmax would be reached if the User made no mistakes any more. Then every pressed key would carry information to the communication partner (Eq. 2). Both variables, Netto-Transferrate and NTR_max are measured in characters per minute. They are shown in Fig. 7 within a period of 30 months. 
Transferrates

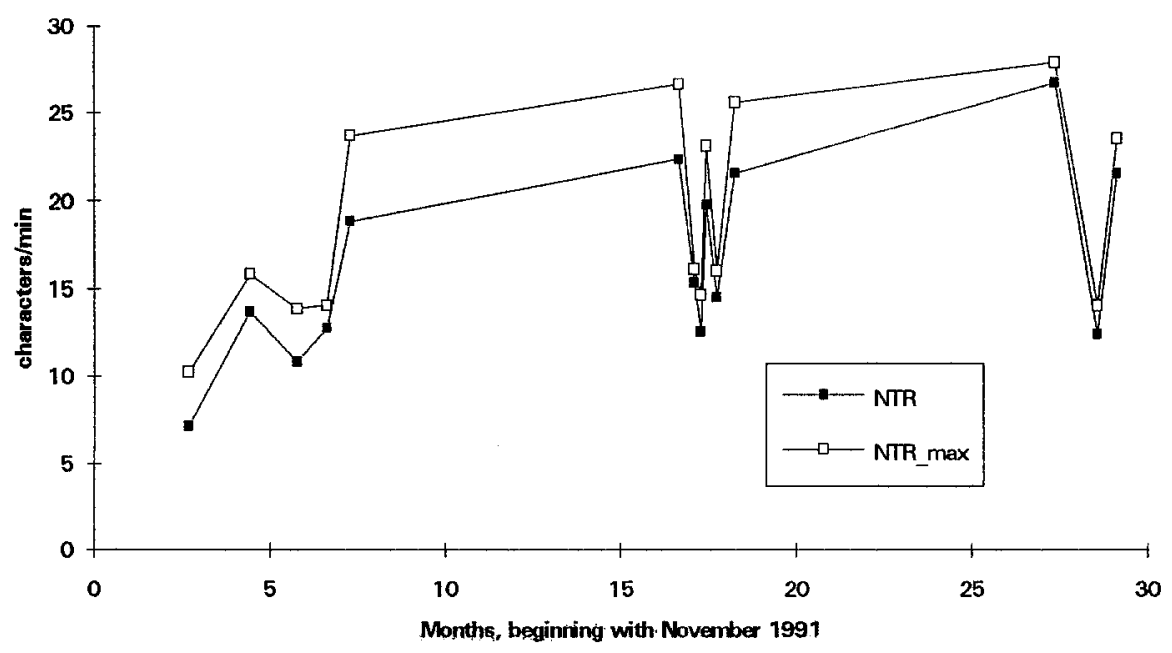

Fig. 7. Netto-Transferrate and its theoretical maximum (NTR_max) of 14 calls with the TINATEL-System.

\section{Interpretation of the Recorded Data}

The recorded data show that the system has had success in getting a good acceptance by the User. The number of telephone calls initiated by the User had an increasing trend within the first months after installation of the system. This fact allows to state that the system is able to meet the most important needs of the User and that it is accepted as an AAC-device by the User.

The manually recorded data of the 14 calls show the effect of training: After having got some practise in using the system the User was able to increase effectiveness of communication. On the other hand the NTR also shows great differences even within short periods of time. This gives a hint of the fact that many extern parameters are influencing the actual transfer rate and effectivness of the system. For example: condition and disposition of the User, abilitiy of the communication partner to interact and to predict characters or words, percentage of communication time spent by the User and spent by the counterpart, and so on. Nevertheless there is a slowly increasing trend recognisable.

The absolut quantity of the NTR variable is much smaller than the transfer rate of unimpaired speech ${ }^{3}$. Even if the average duration of daily use is about the same as

3 The transfer rate of not impaired speech is about 120-200 words per minute [9]. A. Kraat states a rate between 2 and 10 words per minute to be representative for a 
that of a not impaired person using the telephone network, the transferred information is much less. The low input rate of the User seems to be the limiting factor. With the concept of an AAC-device as realised in the TINATEL-System it is not possible to reach the transfer rates of not impaired speech. Therefore alternative ideas for increasing the transferred information are necessary, e.g. published in the work of N. Alm et al. ([1], [2]).

\section{The Significance of Recording Data for the Evaluation of an AAC-device}

The data presented in this evaluation of the TINATEL-System give an example of the possibilities that can be realised by recording the events of daily use. Certainly there are much more things which are worth to be recorded than it is actually done in the system. Some information, for example about the incoming calls is not recorded, also there is no detailed recording of the percentage of time available for the AAC user in comparison with the time used by the communication partner. This important subject is described in the evaluation of the AAC-device "MultiTalk II" done by P. Raghavendra et al. [12].

The long-term evaluation of the TINATEL-System offers information about the long-term use of an AAC-System. In general there are a lot of possibilities created by recording all important events during the use of the system. Questions to be asked during evaluation could be:

- Acceptance of the system: is it really used?

- Suitability: does the system meet what it was planned to meet?

- Transfer rate: in which way does the transfer rate of the evaluated AACdevice differ from the transfer rate which can be reached by other methods?

- How does the way of communication and human interact change?

- Effect of training: does the efficiency of use increase?

- Daily life: is the configuration of the system really adapted to the situation of daily life?

In this way an automatic recording of user events can be a valuable source of information for the evaluation of AAC-devices. It is not able to produce data as objectively as an Assessment Center (see [16], [7], [11]), but gives information of the real life environment. Nevertheless it can not be more than a contribution to an evaluation. The experiences and situations of the users [5], their familiar partners and therapists are essential.

The recording function of the TINATEL-System is a background job. It goes without saying, that the user must be agree to the recording procedure of data.

communication with the help of an AAC-device [9]. P. Raghavendra et al. report a communication rate with Multi Talkll of 11.3-18.8 words/minute [12]. W. Roßdeutscher reports 0.4-5.5 characters per minute for severly handicapped persons who have to use scanning methods to interact with the AAC-device [13]. The User of the TINATELSystem reaches rates of about 20 characters (about $4-5$ words) per minute. 


\section{Future Aspects}

It is planned to integrate the experiences gained with automatic data recording into the implementation of an assistive system to support the independence of elderly and handicapped persons described in [8] and [17]. This system will be installed in a special training-room of a support centre for physically and multiple handicapped persons in spring 1995 . The data which should be recorded there are provided to give an overview of the acceptance of a flexible system for differently impaired users.

\section{References}

1. Alm, Norman; Waller, Annalu; Arnott, John L.; Newell, Alan F.: Improving Assisted Communication with Narrative Texts, in: Proceedings of the Second European Conference on the Advancement of Rehabilitation Technology, ECART2, Stockholm: Swedish Handicap Institute, 1993, p.26.1.

2. Alm, Norman; Newell, Alan F; Arnott, John L.: An Integrated Research Strategy for Improving Communication Systems for Severely Physically Impaired Non-speaking People, in: Ballabio, E.; Placencia-Porrero, I.; Puig de la Bellacasa, R. (Eds.): Proceedings of the 1st TIDE Congress (Technology for the socio-economic Integration of Disabled and Elderly people), Amsterdam: IOS-Press, 1993, p.249-253.

3. Batavia, A.I. and Hammer, G.S.: Towards the Development of Consumerbased Criteria for the Evaluation of Assistive Devices, in: Journal of Rehabilitation Research and Development, Dept. of Veterans Affaires, Vol.27, No.4, (1990), p.425-436. (referred to by [12]).

4. Besio, Serenella and Ferlino, Lucia: Software and Hardware for Mobility Disorders: A Proposal for Evaluation, in: Zagler, W. (Ed.): Proceeding of the 3rd International Conference on Computers for Handicapped Persons, Vienna: Oldenbourg, 1992, p.22-30.

5. Bühler, Christian and Schmidt, Michael: User Involvement in Evaluation and Assessment of Assistive Technology, in: Proceedings of the Second European Conference on the Advancement of Rehabilitation Technology, ECART2, Stockholm: Swedish Handicap Institute, 1993, p.30.1.

6. Bühler, Christian and Heck, Helmut: The versatile communication aid BASKO helps people with speech impairment, in: Journal of Microcomputer Applications (1993) 16, London: Academic Press, 233-241.

7. Craig, Ian; Nisbet, Paul; Odor, Phil; Watson, Marion: Evaluation Methodologies for Rehabilitation Technology, in Ballabio, E.; PlacenciaPorrero, I.; Puig de la Bellacasa, R. (Eds.): Proceedings of the 1st TIDE Congress (Technology for the socio-economic Integration of Disabled and Elderly people), Amsterdam: IOS-Press, 1993, p.238-243. 
8. Flachberger, C.; Panek, P; Zagler, W.: AUTONOMY - A Flexible and Easyto-Use Assistive System to Support the Independence of Handicapped and Elderly Persons, to be printed in: Zagler, W. (Ed.): Proceeding of the 4th International Conference on Computers for Handicapped Persons, Springer, 1994.

9. Kraat, A.: Communication Interaction Between Aided and Natural Speakers: A State of the Art Report, Toronto: Canadian Rehabilitation Council for the Disabled, 1985. (referred to by [2]).

10. Panek, Paul: Tinatel - A Talking Text-Editor with Telephone Interface for Speech Impaired Persons, in: Zagler, W. (Ed.): Proceeding of the 3rd International Conference on Computers for Handicapped Persons, Vienna: Oldenbourg, 1992, p.397-402.

11. Persson, Jan; Brodin, Håkan; Hass, Ursula: Technology Assessment in Rehabilitation: Conceptual Issues and Two Applications, in: Proceedings of the Second European Conference on the Advancement of Rehabilitation Technology, ECART2, Stockholm: Swedish Handicap Institute, 1993, p.20.1.

12. Raghavendra, Parimala and Rosengren, Elisabet: Effectiveness of MultiTalk II as a Voice Output Communication Aid, in: Ballabio, E.; PlacenciaPorrero, I.; Puig de la Bellacasa, R. (Eds.): Proceedings of the 1st TIDE Congress (Technology for the socio-economic Integration of Disabled and Elderly people), Amsterdam: IOS-Press, 1993, p.50-54.

13. Roßdeutscher, Wolfram: Kommunikationshilfen für Schwerstbehinderte, in: Boenick, Ulrich (Ed.): Biomedizinische Technik Forschungsberichte für die Praxis, Bd.4, Berlin: Schiele und Schön, 1992

14. Sandhu, Jim; Mckee, Ian; Carruthers, Stuart: The Role of Evaluation in the Development of Rehabilitation Technolngy Products, in: Ballabio, E.; Placencia-Porrero, I.; Puig de la Bellacasa, R. (Eds.): Proceedings of the 1st TIDE Congress (Technology for the socio-economic Integration of Disabled and Elderly people), Amsterdam: IOS-Press, 1993, p.174-178.

15. Scherer, M. J.: Living in the State of Stuck - How Technology Impacts the Lives of People with Disabilities, Cambridge, MA: Brookline Books, 1993.

16. Spens, K.-E.; Plant, G.; Gnosspelius, J.: Controlling Time Parameters in Connecting Discourse Tracking, in: Proceedings of the Second European Conference on the Advancement of Rehabilitation Technology, ECART2, Stockholm: Swedish Handicap Institute, 1993, p. 4.2.

17. Zagler, W.L. and Flachberger, C.: Autonom - A Remote Control System: An Example for what technology can do, but what technicians don't know, COST AS Workshop on Gerontechnologies, Vienna, 1993. 